\title{
Los programas de resumen futbolístico de TVE durante el monopolio de la televisión pública: características y rasgos de innovación
}

\author{
Joseba BONAUT IRIARTE \\ Universidad San Jorge \\ jbonaut@usj.es
}

Recibido: 04/02/2014

Aceptado: 10/03/2014

\begin{abstract}
Resumen
El siguiente texto aborda un fenómeno poco estudiado por la historiografía televisiva española y que ha condicionado todo el desarrollo de sus contenidos televisivos deportivos: los programas de resumen futbolístico. Este tipo de espacio tiene su origen en Reino Unido durante los años sesenta y se consolida con la aparición de un programa referente de la televisión de ese país: Match of the Day (BBC One, 1964-). En España, y bajo la apariencia de un cierto retraso televisivo, TVE aborda este formato con una clara perspectiva del espectáculo, que condicionará la evolución histórica de la programación deportiva y que será referente en toda Europa. Desde Su equipo fuera de casa (TVE, 1957) hasta Estudio Estadio (TVE, 1972-), la televisión pública experimentó con la hibridación genérica televisiva, cruzando constantemente los terrenos de la información y del entretenimiento, y fomentando muy habitualmente la polémica. Estas páginas realizan un repaso exhaustivo a esta realidad desconocida a través del análisis de la estructura y contenidos de los programas, poniéndola en contexto con otros fenómenos televisivos europeos, y observando su influencia en los actuales formatos de entretenimiento futbolístico.

Palabras clave: TVE, programas de resumen futbolístico, Estudio Estadio, Match of the Day, entretenimiento.
\end{abstract}

\section{TVE's football highlights programmes during TV Public Service monopoly: main features and innovative contributions}

\begin{abstract}
The following text reviews an unknown phenomenon in Spanish Television History which influenced the development of sports content: football highlights programmes. These contents were born in the United Kingdom in the 60s and its main representative was Match of the Day (BBC One, 1964-). In Spain, and despite the poor development of national television, TVE focused in a singular point of view, with a strong presence of entertainment in football highlights programmes, becoming a European reference. From Su equipo fuera de casa (TVE, 1957) to Estudio Estadio (TVE, 1972-), national television experimented with content hybridization, mixing information and Entertainment, and encouraging public controversy. This article presents a deeply review of an unknown issue through a wide analysis of Spanish football highlights programmes and comparing them with other European examples.

Keywords: TVE, football highlights programmes, Estudio Estadio, Match of the Day, entertainment.

Referencia normalizada: BONAUT IRIARTE, Joseba (2014): "Los programas de resumen futbolístico de TVE durante el monopolio de la televisión pública: características y rasgos de innovación". Estudios sobre el Mensaje Periodístico, Vol. 20, Núm. especial, pp. 91-104. Madrid, Servicio de Publicaciones de la Universidad Complutense.

Sumario: 1. Introducción. 2. Breve distinción genérica; 2.1. Retransmisiones deportivas; 2.2. Magacín deportivo; 2.3. Información deportiva; 2.4. Espacios didácticos. 3. El programa de resumen futbolístico: orígenes y evolución histórica. 4. Estudio Estadio y Match of the Day: dos casos paradigmáticos. 5. Conclusiones. 6. Referencias. 7. Programas de TV.
\end{abstract}




\section{Introducción}

En la actualidad, los programas de resumen futbolístico viven en una cierta marginalidad en relación a las grandes retransmisiones en directo y están supeditados a otros espacios donde el entretenimiento es más importante que el hecho noticioso (por ejemplo, Punto Pelota -Intereconomía, 2008-).

El gran objetivo de estos programas era, fundamentalmente, brindar al espectador las mejores jugadas de los partidos que se disputaban en la jornada de Liga. Además, acercaban la realidad y emoción de lo experimentado en directo tan solo unas horas después de que se hubiesen disputado los partidos. En definitiva, vivían del acontecimiento en directo y tenían un carácter puramente noticioso. El aficionado de un equipo quería ver qué había pasado en el encuentro de ese fin de semana y disfrutar, ante todo, de las mejores jugadas y de los goles.

En este sentido, la cobertura total y en directo de todos los partidos, que actualmente marca la programación futbolística española, ha restado interés a estos espacios y los ha convertido en secciones breves de programas contenedores con una visión más analítica y enfocados a la opinión y al entretenimiento (El día del fútbol, Canal Plus, 2005-).

Por ello, si el espectador ya conoce el resultado de un encuentro y, lo más importante, ya lo ha visto, el ámbito noticioso deja de tener importancia y el foco de atención recae en el entretenimiento. La opinión, el debate y el "partido fuera del partido", la polémica, se convierten en hilos conductores de los programas futbolísticos de fin de semana, que buscan ofrecer un punto de vista diferente (como ya comenzó a realizar El día después en Canal Plus desde 1990) y alimentar el forofismo de sus espectadores (desde la tertulia de Punto Pelota, comentada anteriormente, hasta espacios de humor como Crackòvia de TV3).

Sin embargo, para entender esta realidad actual, es necesario realizar el estudio desde la perspectiva histórica de los programas de resumen futbolístico españoles. Fueron claves para el avance de la programación deportiva televisiva y, además, introdujeron gran parte de los rasgos que definen a los espacios de entretenimiento futbolístico.

Los programas de resumen permitieron la difusión y masificación de esta disciplina deportiva, popularizaron a sus protagonistas, facilitaron el desarrollo de las primeras grandes retransmisiones en directo, formaron a los primeros técnicos televisivos en la realización deportiva, proporcionaron cuantiosos ingresos económicos a los clubes a través de los patrocinios (en los programas y en los campos, a través de la difusión televisiva) y, lo más importante, crearon una referencia semanal y, por lo tanto, una costumbre en el aficionado/espectador que quedó fidelizado a la televisión y a la disciplina deportiva. Probablemente no existe un ejemplo más claro de la importancia e influencia del medio televisivo en la creación de una herencia cultural y nacional.

Por ello, en el siguiente texto se explora el origen y desarrollo histórico de los programas de resumen futbolístico durante la primera gran etapa de la historia televisiva: la del monopolio de la televisión pública (1956-1990). El objetivo es determinar los rasgos de estos espacios, su grado de innovación dentro del contexto televisivo europeo $\mathrm{y}$, finalmente, la influencia de estos contenidos en la programación deportiva actual. 
Para conseguirlo, en primer lugar se realiza una breve definición genérica de los distintos tipos de espacios deportivos televisivos existentes. Así se delimitarán claramente las características de los programas de resumen futbolístico. En segundo lugar, se desarrolla un recorrido histórico por los principales hitos de estos contenidos y se compara la realidad española con la de otros mercados, fundamentalmente el británico (principal impulsor del "formato"). En tercer lugar, se realiza un análisis comparativo entre el gran referente español de este tipo de espacios, Estudio Estadio (TVE, 1972), y su homólogo británico, Match of the Day (BBC One, 1964-). Por último, se presentan unas conclusiones que nos darán claves para interpretar la realidad deportiva en la televisión española y su grado de influencia e innovación en el desarrollo histórico del medio.

La estructura y objetivos comentados en los párrafos anteriores se han conseguido a través de la revisión bibliográfica sobre la historia de la televisión española y europea, así como la específica sobre la programación deportiva. Pero los principales resultados se han logrado gracias a un análisis completo de las parrillas de programación desde el año 1956 hasta 1990 (tomando como fuentes los periódicos La Vanguardia, ABC y El País, así como las revistas de TVE, Telediario y Tele Radio), y el visionado completo de los programas aquí presentados en sus fuentes originales (TVE y BBC)1.

\section{Breve distinción genérica}

Antes de iniciar el repaso histórico, es necesario intentar definir el objeto de estudio y realizar unas breves aclaraciones genéricas. En primer lugar, no encontramos una definición exacta de "programa de resumen futbolístico", algo que ya revela su carácter híbrido, con la aparición de contenidos que abarcan la información, el entretenimiento (magacín) o incluso la cobertura en directo de eventos.

En el mundo anglosajón se reduce al concepto de "highlights programme" ("programa con los mejores momentos"), que obliga a la necesaria explicación de la realidad: se trata de contenido deportivo y abarca una especialidad concreta (en este caso, el fútbol).

Por otro lado, es interesante ver cómo un mercado televisivo tan potente como el italiano, y uno de los pioneros en la programación deportiva, ha sido capaz de utilizar una denominación más específica para la compleja realidad de estos contenidos. El término usado ha sido el de "rotocalto televisivo" (algo así como "revista", próximo a la idea de magacín). De esta manera, se define como "aquel programa de televisión con periodicidad concreta, que se ocupa de temas de la actualidad y utiliza reportajes grabados con un estilo formal estandarizado (traducción propia)" (Grasso, 2000: 693).

Con esta definición se relaciona a los programas de resumen futbolístico con el "infotainment" ("infoentretenimiento"), "contenidos o programas informativos que reciben un tratamiento desde la perspectiva del entretenimiento" (Thussu, 2009: 6-7).

1 Este artículo y sus resultados se enmarcan dentro del proyecto "Televisión y cultura popular durante el franquismo: programación, programas y consumo televisivo (1956-1975)". HAR2011-27937, financiado por el Ministerio de Ciencia e Innovación. 
Al margen de estas apreciaciones, se tiende a incluir a este tipo de programa, junto con otros de diferente naturaleza, bajo la denominación genérica de "deportes" ("sports" en el mundo anglosajón). Concepto limitado pero que abarca la totalidad de posibilidades televisivas: retransmisiones en directo, programas contenedores con eventos en directo y resúmenes y otras derivaciones (Rose, 1985).

Esta importante indefinición terminológica y genérica ha tenido su reflejo en la reflexión académica. Existen muy pocos estudios en nuestro país que traten la realidad del deporte televisado y, en los existentes, se alejan de cualquier intento de delimitar la función de estos contenidos y la tipología de los mismos (Bonaut, 2009: 11-12).

Si nos trasladamos al ámbito profesional, las televisiones y las empresas que se encargan de medir sus audiencias definen a estos programas como "deportes" frente al resto de géneros (así ocurre tanto en los informes de la Unión de Televisiones Comerciales Asociadas -UTECA- como los de Kantar Media): ficción, información, culturales, infoshow, musicales, religiosos, programas de ventas, concursos, toros, miscelánea y otros no categorizables (Anuario de audiencia de la televisión, 2008).

Si realizamos un análisis más profundo de estos informes y mediciones de audiencias, observamos que los "deportes" solo se distinguen por su especialidad deportiva y no por otras variables, como podría ser el tipo de contenido o el tratamiento del mismo. De este modo es obligada una categorización más profunda, previa definición del concepto de programación deportiva.

Si por programación deportiva entendemos el contenido televisivo que tiene al deporte como centro de su estructura (Bonaut y Ojer, 2012: 80-81), el abanico de posibilidades que podemos encontrar es muy variado (desde retransmisiones en directo hasta documentales o programas educativos).

Teniendo en cuenta esta idea, y con el objetivo de poder definir mejor a los programas de resumen futbolístico, agruparemos los espacios deportivos en cuatro categorías que parten de la división básica entre las retransmisiones en exteriores y los programas de estudio (Barroso, 2002: 448-449):

- Retransmisiones deportivas

- Información deportiva

- Magacín deportivo

- Espacios didácticos

\subsection{Retransmisiones deportivas}

Por retransmisión se entiende la emisión de un acontecimiento deportivo, ya sea en directo o en diferido, que se realiza fuera de los estudios de televisión. Es decir, en espacios exteriores. Es la pieza estrella de la programación deportiva y fue uno de los primeros contenidos a los que recurrió el medio para liberarse de la dependencia del plató y diversificar la oferta televisiva. En nuestro país, el referente es la retransmisión futbolística que, si tomamos los resultados del año 2012, ocupó 38 de los 40 espacios con mayor audiencia en España (Anuario de audiencia de TV, 2013).

En esta clasificación incluimos también todos los espacios "contenedores". Programas en los que se enlazan varias retransmisiones que se disputan habitualmente du- 
rante el fin de semana a través de un presentador de estudio. En nuestro país, el primer gran ejemplo de este tipo de espacio fue Estadio 2 (TVE 2, 1984-2007).

Las retransmisiones fueron claves para el desarrollo de la programación en exteriores y la mejora tecnológica, y centran su atención en el fútbol (fundamentalmente el Campeonato Nacional de Liga, Copa de Europa/Champions League y competiciones de selecciones) y grandes acontecimientos deportivos como los Juegos Olímpicos.

\subsection{Magacín deportivo}

El magacín es un tipo de programa que tiene sus orígenes en los comienzos de la televisión, muy arraigado en Europa, y que define muy bien a la "paleotelevisión": un modelo en el que la televisión de Estado es la referencia y en el que no existe una estrategia clara de programación (Cortés, 1999: 17). La hibridación es lo que define al magacín, ya que recoge enfoques de múltiples géneros y ofrece una importante variedad de temas. Se caracteriza por su amplia duración y por tener una periodicidad muy clara y determinada (Gómez, 2005: 1).

En el ámbito deportivo, vive de la presencia en estudio y el reportaje es su eje fundamental. Pero, al mismo tiempo, no puede existir sin la referencia del acontecimiento noticioso, de la competición deportiva y del evento (del que obtiene su materia prima para los reportajes). Es un espacio híbrido entre la retransmisión y los programas informativos, con una duración entre los 30 minutos y la hora de duración de media.

Su mayor virtud es la de "fidelizar" a la audiencia y retroalimentar a las retransmisiones deportivas periódicas, como las que tienen lugar los fines de semana. En nuestro país, y como veremos posteriormente, aquellas relacionadas con el fútbol y el Campeonato Nacional de Liga fueron claves. Buenos ejemplos fueron Su equipo juega fuera de casa (TVE, 1957-1959), Primera División (TVE, 1959-1963), Graderio (TVE, 1964-1965), Ayer domingo (TVE, 1965-1972), y, especialmente, Estudio, Estadio (TVE, 1973-). Muchos de estos casos son programas de resumen futbolístico, que encuentran en esta tipología genérica su mejor encaje.

\subsection{Información deportiva}

Los contenidos informativos son tan antiguos como el propio medio. Hacen referencia a "enunciados televisivos sobre acontecimientos que se verifican independientemente del medio y que pueden hacerlo de forma oral, en directo, diferido, mediante filmaciones o en estudio" (Eco, U., 1973: 32).

Abarcan múltiples temáticas, entre la que destaca la deportiva. Se basan en el reportaje grabado, los testimonios en directo y, de manera muy importante, en las transiciones de un presentador en estudio. Suelen ser habitualmente en directo y ocupan un lugar clave en la estrategia de las cadenas (Marín, 2004).

En este contexto, los programas informativos deportivos han tenido siempre un espacio en los grandes informativos generales, aunque su duración ha variado del minuto en las primeras transmisiones (1957) hasta la media hora en el año 2013 (el caso de Cuatro o La Sexta). Actualmente, la presencia del deporte en los principales espacios informativos representa más de un $20 \%$ del tiempo total de los mismos (Consumer, 2002). 
Es tal su importancia que en muchas ocasiones se convierte en un espacio independiente. Los ejemplos actuales de Cuatro o La Sexta no son nada novedosos, ya que en 1958 encontramos numerosos ejemplos de espacios informativos independientes que buscan acercar la última hora deportiva y cuya duración se extiende a los 15 o 30 minutos: Actualidad deportiva (TVE, 1958-1959), Mañana fútbol (1958) o Información deportiva (TVE, 1959).

\subsection{Espacios didácticos}

Por último, se puede destacar otra categoría dentro del género "Deportes" que tuvo gran relevancia durante el período estudiado (principalmente durante el franquismo), y que busca el fomento de la práctica deportiva así como el mayor conocimiento de su historia y naturaleza: los espacios didácticos.

Estos programas tienen al documental y al reportaje como hilos conductores, la presencia del directo es nula, así como muy escasa la del presentador en el estudio. Las grabaciones que sostienen estos programas se centran en la historia del deporte, sus reglas, funcionamiento, así como circunstancias concretas de las más diversas disciplinas deportivas y de las principales competiciones tanto nacionales como internacionales.

Un acontecimiento importante (Juegos Olímpicos), efeméride (centenario de una disciplina deportiva), o la aparición de un deportista estrella son elementos que impulsan estos espacios. Desde el origen del medio han estado presentes y son múltiples los ejemplos: Aprende un deporte (TVE, 1958-1959), Las reglas del fútbol (TVE, 1958), Deporte, nuevo humanismo (TVE, 1968) o Chócala (TVE2, 1991-1992).

En definitiva, y tras realizar esta división de especialidades en la categoría "Deportes", podemos observar la extrema dificultad para definir a los programas de resumen futbolístico. Sin embargo, la hibridación, los múltiples enfoques, el evento como referencia y el uso del reportaje, nos permiten clasificar a los espacios de resumen futbolístico dentro del magacín, con una importante capacidad para modificarse y adaptarse a otras categorías. Ahora es momento de conocer algo mejor su origen y evolución histórica.

\section{El programa de resumen futbolístico: orígenes y evolución histórica}

La historia de los primeros años de la programación deportiva en España es el relato de una carrera por llevar a los espectadores la emoción de la última hora de la actualidad y, muy especialmente, por conseguir una presencia habitual de los grandes eventos en directo, fundamentalmente los futbolísticos.

Este fenómeno no se restringe a nuestro país, de hecho, los orígenes del medio televisivo en Europa están marcados por los esfuerzos en la retransmisión de los encuentros futbolísticos. En Reino Unido, por ejemplo, con tan solo dos años de vida, la $\mathrm{BBC}$ logró emitir los primeros partidos de fútbol del mundo: un encuentro entre Inglaterra y Escocia en el estadio de Wembley el 9 de abril de 1938 y, el 30 del mismo mes, la final de la Copa Inglesa entre el Preston North End y al Huddersfield Town (Geoffrey, 1949).

En Italia, ya un año antes de comenzar con sus emisiones regulares (1953), la RAI emitió los primeros encuentros de fútbol en los que la selección nacional fue prota- 
gonista. Y un año más tarde logró, junto con el apoyo de otras televisiones europeas, que se retransmitiesen los primeros partidos de una Copa del Mundo, la celebrada en Suiza (Gómez de Marcos, 1988: 5).

TVE siguió este modelo con una emisión experimental de un encuentro del Campeonato Nacional de Liga disputado entre el Real Madrid y el Racing de Santander el 24 de octubre de 1954. Sin embargo, las emisiones en directo eran muy complejas por las dificultades técnicas existentes, el recelo de las instituciones deportivas (insistían en que la presencia de las cámaras reducía la asistencia a los campos) y el limitado desarrollo de las redes de transmisión del momento, especialmente en España (Bonaut, 2008: 108).

Es por ello, que ya en estos años surgen los primeros programas que buscan acercar la actualidad futbolística a través de reportajes filmados y con una presencia periódica en la parrilla de programación. Con este espíritu surgen los programas de resumen futbolístico.

Italia fue el país pionero al introducir en su programación el espacio La domenica sportiva (RAI, 1954-). Este programa, situado estratégicamente en la tarde de los domingos, empezó a ofrecer reportajes con resúmenes de los partidos disputados en el campeonato nacional de liga horas antes. Nada más acabar la jornada mostraba a los espectadores las mejores jugadas y, lo más importante, todos los goles marcados.

Desde 1954, año de nacimiento del espacio, La domenica sportiva fue mejorando progresivamente la calidad de sus reportajes y los fue complementando con entrevistas tras los encuentros, con las declaraciones de los protagonistas e información de última hora. Las limitaciones técnicas de los primeros años se solventaban con informaciones de otros deportes, pero siempre sin perder de vista al fútbol como hilo conductor. Este programa continúa en emisión actualmente y fue referencia para el resto de televisiones, muy especialmente para España (Grasso, 2000: 488-490).

Reino Unido fue otro país pionero en la puesta en marcha de este tipo de contenidos. Allí destacaron dos programas. El primero fue Sports Special (BBC, 1954-1963) que nació en 1954 en la noche del sábado del primer canal de la BBC (22:00-22:30 horas). Incluía las imágenes más interesantes de los tres encuentros destacados de la jornada y añadía entrevistas, noticias de fútbol y contenidos informativos de otros deportes.

Sports Special era un espacio de media hora de duración que se dirigía a los amantes del deporte y, en particular, a los aficionados al fútbol. Tuvo un gran éxito de crítica a pesar de soportar continuos problemas técnicos y de coordinación con los centros regionales que proporcionaban la mayor parte de las imágenes. Ese fue su principal problema, la ausencia de imágenes de calidad y la preponderancia de la palabra (Briggs, 1979: 850-851).

En 1964, Sports Special fue sustituido por el segundo programa de referencia de la televisión deportiva británica: Match of the Day. Este espacio siguió el ejemplo de Sports Special al ofrecer las mejores imágenes del torneo de Liga de Inglaterra pero, al contrario que Sports Special, se centraba completamente en el fútbol y no había tiempo para otros deportes. La base del programa era la emisión de un amplio resumen del partido de la jornada (de ahí su nombre original en inglés) que de alguna manera resolvía el vacío de transmisiones en directo que existía en Inglaterra. 
Match of the day se emitía en la noche del sábado por el segundo canal de la BBC, para pasar en 1966 a la primera cadena tras recibir el respaldo de crítica y público. Match of the day se programaba a mitad de semana en caso de que hubiese jornada de fútbol y sirvió como escenario para la retransmisión de partidos en directo y en diferido de la Copa Inglesa y de la selección nacional, de los que tenía derechos de emisión la BBC.

A pesar de no poseer los derechos de la Liga de fútbol durante algunos períodos de los ochenta y noventa, así como sufrir una feroz competencia de su programa rival en la ITV, The big match (ITV, 1968-1992), Match of the day tuvo una presencia habitual en la programación de la $\mathrm{BBC}$ y está considerado como uno de los programas más importantes de la historia de la televisión británica (Barnett, 2001: 17 y 48).

Con estos dos ejemplos se pueden observar algunos rasgos distintivos de estos programas: dificultades técnicas con las imágenes de los encuentros, problemas con los derechos de retransmisión (en primer término, la imposibilidad de las televisiones de emitir en directo esos encuentros), escaso margen de tiempo entre su emisión y el evento futbolístico, importancia esencial del resumen grabado y de los goles como referencia, elementos complementarios al resumen y la información (por ejemplo las entrevistas) y una presencia decisiva de las competiciones domésticas.

La televisión española siguió esos modelos, pero tuvo un contexto algo diferente ya que desde 1963 las retransmisiones regulares en directo de partidos de liga se institucionalizaron. Este caso único en Europa, el siguiente país en hacerlo fue Inglaterra en 1983, condicionó el desarrollo de los programas de resumen e intensificó el interés del espectador por los mismos (Tele Radio, 1963: 17).

Dentro de los espacios más importantes del período destacó Estudio Estadio (TVE, 1972-), muy influido por Match of the Day y La domenica sportiva. Sin embargo, no se puede entender Estudio Estadio sin otros espacios que conformaron las características del programa de resumen futbolístico como Su equipo juega fuera de casa, Primera División (TVE, 1959-1963), Graderio o Ayer domingo (Tele Radio, 1969: 12-13).

A este respecto, es fundamental destacar la figura de Miguel Ors, pionero con la puesta en marcha de todos estos espacios. La idea de Su equipo juega fuera de casa llegó cuando Ors viajó con el Real Madrid en 1957 a Granada y filmó con su cámara algunas imágenes del partido. A su regreso, TVE emitió un reportaje de dos minutos que tuvo un gran éxito y que permitió la creación de un espacio independiente. $S u$ equipo juega fuera de casa recogía las mejores imágenes del partido que jugaba uno de los equipos madrileños como visitante, ya que todavía la televisión llegaba únicamente a Madrid. El propio Ors filmaba el encuentro, mientras que las imágenes del partido de casa del otro equipo madrileño las grababa el cámara Valentín López. El programa se emitía en la noche del lunes (Tele Radio, 1970: 18-20).

Con la llegada de la televisión a Barcelona, el programa amplió sus resúmenes a los equipos catalanes y ofreció las mejores imágenes de los partidos de los conjuntos de Madrid y de la ciudad condal. La realización correspondía a Ors y los comentarios a Matías Prats. 
Con la extensión de la cobertura de TVE por el territorio nacional, se creó una red de corresponsales dirigida por el propio Ors que grababa las imágenes de los encuentros en las diferentes ciudades: Bilbao, Santander, Valencia, San Sebastián, Sevilla, etc.

Esta ampliación progresiva provocó el cambio de nombre en el programa que tomó a finales de 1959 el nombre de Primera División. Cada equipo tenía sus dos minutos de protagonismo en el espacio con el resumen de las mejores jugadas de los encuentros. El programa, sin sufrir grandes cambios, cambió su nombre por el de Graderío y, finalmente, Ayer domingo a partir de 1965. Siempre, en la noche del lunes.

El procedimiento de producción del programa era muy complicado. Se filmaban 30 minutos de cada partido y luego se enviaban a Prado del Rey por avión o tren. Posteriormente, se revelaban y se elaboraban los resúmenes de dos minutos de cada partido en el que la prioridad era mostrar los goles marcados. Muchas veces, los retrasos en los aviones provocaban que algunos resúmenes no se emitiesen o se hicieran de forma improvisada, sin la necesaria comprobación previa (Tele Radio, 1969: 12-13).

En septiembre de1972, Estudio Estadio recogió el testigo de Ayer domingo y tomó la base de este programa a la que añadió las mejoras que la tecnología proporcionaba en esas fechas: la emisión de las mejores imágenes el propio día de los encuentros y la repetición. En esta primera etapa, fue un joven Pedro Ruiz (25 años) quien llevó las riendas del programa mientras que Ors se situó en la dirección.

Como veremos en el próximo epígrafe, la introducción de la sección la "moviola" fue clave para que el programa se popularizase y se convirtiese en la referencia definitiva de la programación deportiva. Al elemento noticioso se añadía, por primera vez, un componente de entretenimiento. Se ponían las bases del programa deportivo moderno en nuestro país.

La "moviola" presentaba las jugadas más polémicas de los encuentros de fútbol, que se analizaban con detalle gracias al uso de la repetición. Esto no era una novedad ya que se utilizaba en otros países como en Italia. El hecho novedoso es que se convirtiese en el reclamo principal del público y luego pieza básica del espacio. La moviola fue posible, como explica Pedro Ruiz, "gracias a un aparato llamado videodisco, que ya utilizaba la RAI. Yo no veía las jugadas previamente, lo hacía a la vez que los espectadores. Fue un punto de inflexión porque empezó a generar polémica y los futboleros discutían con más fervor" (El País, 2002).

Estudio Estadio también fue pionero al introducir la presencia de un árbitro para comentar las jugadas polémicas, José María Ortiz de Mendívil, así como a la primera mujer periodista deportiva, Mari Carmen Izquierdo (ABC, 2002). La última hora de la información, las entrevistas y los protagonistas de la jornada completaron la oferta de un espacio que durante 30 años llevó la emoción del mejor fútbol español y, sobre todo, el espectáculo.

\section{Estudio Estadio y Match of the Day: dos casos paradigmáticos}

Una vez realizado el repaso histórico, es necesario desarrollar un análisis comparativo entre el principal referente español del período, Estudio Estadio, y el emblema de la programación deportiva británica, Match of the Day. El contraste de estos dos ejemplos nos permitirá obtener conclusiones evidentes sobre los rasgos de originalidad e influencia del programa español. 
Para concretar estas características, se ha analizado una muestra de dos programas por año en el período en el que estos dos espacios han coincidido dentro del monopolio de la televisión pública en España: desde 1972 hasta el año 1990.

El visionado ha sido posible gracias a los archivos de RTVE y de la BBC (dentro del British Film Institute), y se han analizado los siguientes elementos: duración, estructura narrativa (secciones, número de reportajes, duración de los mismos, tipo de material, narrador), presentador, tipología del contenido y elementos audiovisuales utilizados (imágenes y sonidos).

Tras el visionado y análisis, podemos distinguir los siguientes rasgos definitorios de los programas de resumen futbolísticos:

Son espacios dedicados en su totalidad al fútbol y concentrados en la mayor parte de su tiempo a la competición de Liga (en todo caso, siempre competiciones locales). Match of the Day sí que dedica un tiempo importante a la copa inglesa, por la tradición de la misma, que se suele ubicar los fines de semana entre la competición liguera.

Son programas que tienen la figura de un conductor/presentador estrella. Es una figura reconocida que se asocia con los contenidos deportivos y, en muchos casos, con las retransmisiones en directo. El caso de Pedro Ruiz en los orígenes puede ser una excepción muy interesante, por su orientación al mundo del espectáculo. Posteriormente, su puesto lo han ocupado figuras relacionadas con el periodismo deportivo de forma tradicional, como Matías Prats. En el caso británico, este puesto lo ocuparon grandes referencias deportivas como David Coleman, Jimmy Hill o Des Lynam.

Los programas tienen una duración media de 60 minutos. Estudio Estadio se limitó a los 30 minutos durante sus cinco primeros años y luego alargó su duración hasta los 60 minutos. Cuando se introdujeron nuevas secciones no informativas, el programa se amplió hasta los 90 minutos. En el caso de Match of the Day su duración fue estable en los 60 minutos hasta los últimos años del estudio, que llegaría a los 90.

- La estructura del programa se puede sintetizar de la siguiente manera:

- Cabecera con sintonía: 1 minuto.

- Presentación del conductor: 1 minuto.

- Sumario: 1 minuto.

- Resultados y clasificación: 5 minutos.

- Resultados de apuestas (en España la Quiniela): 1 minuto.

- Entradillas del presentador a los reportajes: 2 minutos.

- Reportajes (en el caso de Match of the Day hasta 1983, un solo reportaje): 30 (45 cuando había un reportaje).

- Reacciones y entrevistas (entre reportajes): 5 minutos.

- Jugadas polémicas (la Moviola en Estudio Estadio): 10 minutos.

- Breves y despedida: 3 minutos.

- Cabecera con sintonía: 1 minuto.

- Los programas se definen por un contenido informativo en casi un $80 \%$ de su tiempo. El 20\% restante se reserva al debate, que se concentra en la polémica de las jugadas más dudosas y en noticias conflictivas (en el caso británico, la violencia en los campos ocupa un puesto muy relevante). 
- La referencia informativa tiene como principal herramienta el reportaje del resumen de los encuentros más destacados.

- El reportaje varía en su número dependiendo del enfoque del programa y la situación de los derechos de retransmisión en directo. Cuando existen retransmisiones en directo, los reportajes se multiplican para cubrir toda la realidad de la competición nacional (es así en el caso de Estudio Estadio, y en el caso de Match of the Day cuando se establecen las retransmisiones en directo en el año 1983). La duración media de estos reportajes no superará nunca los cinco minutos. Cuando no existen retransmisiones en directo (el caso británico hasta 1983), el programa se centra en un gran reportaje de 45 minutos que aborda el partido más importante de la jornada.

- Por lo tanto, la existencia de retransmisiones en directo y la posesión de los derechos de las retransmisiones van a determinar el enfoque de los reportajes: numerosos y breves o limitados y simulando la retransmisión en directo.

- Los reportajes se nutren de imágenes registradas por los equipos de grabación de las cadenas y reflejan de forma condensada los mejores momentos de cada partido. Además, son reportajes editados en los que el fin último es reflejar los goles y las mejores jugadas en su máximo esplendor. Por lo tanto, la repetición y la cámara lenta predominan frente a la acción real. Por otro lado, la presencia de un narrador que comenta las jugadas es habitual y la rotulación con los goleadores y minutos de los tantos complementan la información.

- Los reportajes tienen breves complementos de testimoniales/entrevistas que suelen ubicarse al final de las piezas y busca captar la reacción de los protagonista.

- Los reportajes de los encuentros se definen por su "simulación" o "recreación" del evento en directo. Existen dos fórmulas: aquella que simula un "falso directo" u otra en la que se hace uso de la técnica de la crónica. En ninguno de los dos casos se utilizan técnicas de la ficción audiovisual y el peso del entretenimiento es nulo.

- La información práctica tiene un peso importante dentro de los programas. Es una información que debe ubicar al espectador en aspectos básicos: resultados de los partidos por jornada y categoría, clasificación, máximos goleadores, siguiente jornada y, finalmente, resultados de apuestas (la Quiniela en el caso español).

Esta información práctica se presenta de una manera bastante rudimentaria, con rótulos escritos a mano o gráficos muy sencillos. Son textos comentados por el conductor del programa. La información se complementa con noticias breves al final del espacio.

- Por otro lado, el entretenimiento tiene una presencia decisiva (y única en relación con otros contenidos deportivos) a través del repaso de las jugadas polémicas. En estas secciones surgen nuevas figuras que debaten sobre si el árbitro ha acertado o no. Al presentador se le unen periodistas, futbolistas y árbitros.

El debate es medio utilizado para alimentar estas secciones que en Estudio Estadio alcanzó una popularidad jamás vista (la "moviola"). El centro del debate se articula gracias a las imágenes registradas de los partidos y al uso de la repetición y la cámara lenta. Este recurso seguirá existiendo en estos programas y en otros con diferente estructura hasta nuestros días (un ejemplo muy claro es "el líbero" de El día 
del fútbol, en el que la polémica se decide a través de la reconstrucción en 3D de las jugadas).

- La presencia en minutos de la polémica y este contenido de entretenimiento será cada vez mayor con el paso del tiempo, en cuanto que las emisiones en directo sean más numerosas y frecuentes. Estas secciones plantean un cambio en el paradigma del programa deportiva: de la información y el directo al entretenimiento del directo.

No se puede obviar, dentro de la configuración de estos programas, del uso de un sintonía característica que por su presencia habitual quedará ligada al recuerdo colectivo de los espectadores. En otros países, como en Estados Unidos, la sintonía de cabecera podía ser un buen reclamo para potenciar la espectacularización del contenido presentado (el ejemplo más claro es el del Monday Night Football-ABC, 1970/2005-).

- $\quad$ En los dos casos, la presencia de contenidos que no se situasen en el estudio eran prácticamente nulos ya que se trabajaba con una realidad: la jornada había acabado y el programa funcionaba como crónica de la misma.

Estos son algunos de los rasgos más destacados que ofrece el análisis de los programas a lo largo de este período del monopolio de la televisión pública y en dos casos paradigmáticos del mercado europeo. Lo más interesante es descubrir gran parte de las características que han marcado a los contenidos deportivos en los últimos años y confirmar la dificultad para definir a estos programas dentro de una categoría genérica. Por último, el ejemplo español se presenta como un modelo pionero en el uso del entretenimiento pero algo retrasado en la utilización de la tecnología televisiva.

\section{Conclusiones}

Tras los comentarios realizados en las páginas anteriores, se pueden extraer las siguientes conclusiones:

- Los programas de resumen futbolístico son espacios de difícil categorización pero que presentan características únicas en la programación deportiva. La combinación del entretenimiento con la información los convierten en espacios pioneros y modelos para la evolución futura.

Son contenidos que viven de las retransmisiones en directo y la situación de las mismas (presencia habitual, posesión de los derechos de emisión) determina su desarrollo y configuración.

- Los programas de resumen futbolístico son un buen medio para la difusión de esta disciplina deportiva, creando por su periodicidad y cobertura una gran fidelidad con el espectador. Algo que demuestra el tiempo que estos espacios permanecen en pantalla (casi 40 años en los casos estudiados).

- El uso que realizan del reportaje y la tecnología son claves. El reportaje es su hilo narrativo y la tecnología permite revivir y disfrutar del fin último de estos espacios: mostrar las mejores jugadas y celebrar el triunfo y belleza del gol (aquello que buscan los espectadores).

- Esta última idea es esencial ya que permiten reforzar la memoria colectiva de los aficionados al fútbol y de los telespectadores en general. 
- $\quad$ En este contexto, la evolución histórica de estos programas en España es similar a la de otros países con la salvedad de las presencia de retransmisiones en directo desde muy pronto (1963). Esta circunstancia no hará sino aumentar la fidelización de los aficionados.

El caso de Estudio Estadio es un fiel reflejo del carácter innovador de los contenidos deportivos españoles. La búsqueda del espectáculo, a través de la polémica, abrirá una línea de contenido inédita en otros países, e influirá directamente en el desarrollo de otros formatos deportivos en España.

\section{Referencias}

ANIORTE, Carmen (2002): "Estudio Estadio: 30 años de moviola", en $A B C, 10$ de febrero, sección televisión.

BARNETT, Steven (2001): Games and Sets: the changing face of sport on television. London, BFI.

BARROSO, Jaime (2002): Realización de los géneros televisivos. Madrid, Síntesis.

BONAUT, Joseba (2008). "La influencia de la programación deportiva en el desarrollo histórico de TVE durante el monopolio de la televisión pública(19561988)". Comunicación y sociedad, vol. XXI, $\mathrm{n}^{\circ} 1$. Pamplona, Universidad de Navarra, pp. 103-136.

BONAUT, Joseba (2009): Televisión y deporte. Origen y desarrollo histórico de la programación deportiva española (1956-1975). Buenos Aires, Libros en red.

BONAUT, Joseba y OJER, Teresa (2012): "Programación deportiva en la televisión franquista: la conquista de la calidad a través de la innovación". Anàlisi. Quaderns de comunicació i cultura, $\mathrm{n}^{\circ}$ 46. Barcelona, Universitat Autònoma de Barcelona, Facultat de Comunicació, pp. 69-87

BRIGGS, Asa (1979): The History of the Broadcasting in the United Kingdom. Oxford, Oxford University Press.

CONSUMER (2002): "Deporte y política acaparan cerca de la mitad de los telediarios". Consumer. La revista del consumidor de hoy, $\mathrm{n}^{\circ} 58$. Valencia, Consum Publicaciones, pp. 1-7.

CORTÉS, José Ángel (1999): La estrategia de la seducción: la programación en la neotelevisión. Pamplona, EUNSA.

ECO, Umberto (1973): Apocalípticos e integrados ante la cultura de masas. Barcelona, Lumen.

GALLO, Isabel (2002): "Estudio Estadio celebra su $30^{\circ}$ aniversario con Johan Cruyff y Raúl", en El País, 9 de febrero, sección televisión.

GEOFFREY, Green (1949): The official history of the F.A. Cup. London, Heinemann. GÓMEZ MARTÍN, Mónica (2005): "Los nuevos géneros de la neotelevisión”. Área abierta, $\mathrm{n}^{\circ}$ 12. Madrid, Ediciones UCM. Referencia: AA12.0603.69. 
GÓMEZ DE MARCOS, Fernando (1988): Historia, estructura y funcionamiento de la Unión Europea de Radiodifusión (UER). Madrid, Instituto Oficial de Radio y Televisión.

GRASSO, Aldo (2000): Storia della televisione italiana. Milano, Garzanti.

KANTAR MEDIA (2013): Anuario de audiencia de TV. Madrid, Ediciones Kantar Media.

MARÍN, Carles (2004): El lenguaje en los informativos de televisión. Palma de Mallorca, Calima ediciones.

ROSE, Geoffrey (1985): TV Genres: a Handbook and Reference Guide. Westport, Greewnwood.

TELE RADIO (1963): “TVE retransmitirá varios partidos de fútbol de la actual temporada". Tele Radio, no 304. Madrid, TVE, p. 17.

TELE RADIO (1969): “Ayer domingo”. Tele Radio, nº 592. Madrid, TVE, pp. 12-13.

TELE RADIO (1970): “Ayer domingo”. Tele Radio, n 639. Madrid, TVE, pp. 18-20.

THUSSU, Daya (2009): News as Entertainment. The Rise of Global Infotainment. University of Westminster, Sage Publications Ltd.

TNS (2008): Anuario de audiencia de la televisión. Madrid, TNS ediciones.

\section{Programas de TV}

Actualidad deportiva (TVE, 1958-1959)

Aprende un deporte (TVE, 1958-1959)

Ayer domingo (TVE, 1965-1972)

Chócala (TVE2, 1991-1992)

Crackòvia (TV3, 2008-)

Deporte, nuevo humanismo (TVE, 1968)

El día del fútbol (Canal Plus, 2005-)

El día después (Canal Plus, 1990-)

Estadio 2 (TVE 2, 1984-2007).

Estudio Estadio (TVE, 1972-)

Graderio (TVE, 1964-1965)

Información deportiva (TVE, 1959).

La domenica sportiva (RAI, 1954-)

Las reglas del fútbol (TVE, 1958)

Mañana fútbol (1958)

Match of the Day (BBC One, 1964-)

Monday Night Football (ABC, 1970-2005)

Primera División (TVE, 1959-1963)

Punto Pelota (Intereconomía, 2008-)

Sports Special (BBC, 1954-1963)

Su equipo juega fuera de casa (TVE, 1957-1959)

The big match (ITV, 1968-1992) 